\title{
Analysis and simulation of nutrient retention and management for a lowland river-lake system
}

\author{
D. Kneis ${ }^{1}$, R. Knoesche ${ }^{2}$, and A. Bronstert ${ }^{1}$ \\ ${ }^{1}$ Institute of Geoecology, Potsdam University, Germany \\ ${ }^{2}$ Institute of Biology and Biochemistry, Potsdam University, Germany
}

Received: 19 September 2005 - Published in Hydrol. Earth Syst. Sci. Discuss.: 30 November 2005

Revised: 11 May 2006 - Accepted: 29 May 2006 - Published: 8 August 2006

\begin{abstract}
In the context of the European Water Framework Directive, we studied the possible impact of reduced emissions on phosphorus and nitrogen concentrations in a lowland river-lake system (Havel River, Germany). As a prerequisite, we quantified the retention of nutrients in the river from mass balances and deduced its seasonal variation. We detected that about $30 \%$ of the total nitrogen input is retained within the surveyed river section. In contrast, phosphorus release from sediments was shown to cause a considerable increase in present $\mathrm{P}$ concentrations. Average net phosphorus release rates of about $20 \mathrm{mg} \mathrm{P} \mathrm{m}^{-2} \mathrm{~d}^{-1}$ in late summer were estimated for the Havel Lakes. Based on the observed patterns of $\mathrm{N}$ retention and $\mathrm{P}$ release we parametrized a newly developed water quality simulation program (TRAM), which allows alternative model approaches of different complexity to be implemented and tested. To account for the future trend of internal P loading, the phosphorus excess in lake sediments was estimated from core samples and included in the model as a state variable. For analyzing scenarios of reduced nutrient emissisions, the water quality simulation program was linked to mesoscale hydrological catchment models for the first time. From scenario simulations we conclude that internal P loading is likely to counteract efforts of emission control for decades. Even by significant reductions in external P loads, a persistent phosphorus limitation of primary production can hardly be established in the analyzed time frame of 13 years. Though in the short run a continued reduction in nitrogen loads appears to be the more promising approach of eutrophication management, we recommend enhanced efforts to diminish both $\mathrm{N}$ and $\mathrm{P}$ emissions.
\end{abstract}

Correspondence to: D. Kneis

(dkneis@uni-potsdam.de)

\section{Introduction}

In many river basins, eutrophication is one of the major water quality problems. In search of adequate management options, eco-hydrological catchment models are frequently used for quantifying the impact of reduced nutrient emissions from point and non-point sources (e.g. Schreiber et al., 2005; Kronvang et al., 1999). The representation of individual water bodies in these catchment studies is mostly poor. However, the focus of the European Water Framework Directive (EU-WFD) is just on the ecological status of individual lakes and river sections. In order to overcome this discrepancy, catchment models need to be linked to water quality models of adequate spatial and temporal resolution and appropriate complexity (e.g. Van Griensven and Bauwens, 2003).

Special problems arise in case of regulated lowland rivers or river-lake systems. Often, the adequate representation of the hydrological system is a challenge on its own. Furthermore, the impact of elevated nutrient loading is more serious in lakes and slowly flowing rivers. Due to the prolonged residence time of the water, primary production in the pelagic becomes important and the dynamics of nutrient concentrations are largely controlled by biological turnover. Also, sedimentwater interactions often gain in importance.

The work presented here is part of a research project which aimed at assessing different options for improving the trophic state of the Lower Havel River. For that, we coupled the two catchment models SWIM (Krysanova et al., 2000) and ArcEGMO-Urban (Biegel et al., 2005) to a newly developed open-structure water quality simulation program TRAM. The formulation and parametrization of the water quality model was supported by limnological field research.

We present selected results of our research in the following steps:

First of all, we examine the retention of nutrients in the Lower Havel River with a high temporal resolution. While phosphorus dynamics were already studied by Hoffmann

Published by Copernicus GmbH on behalf of the European Geosciences Union. 


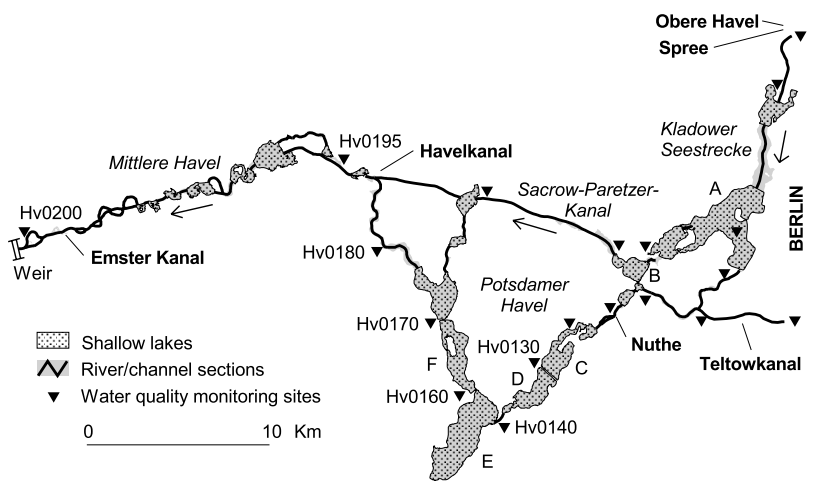

Fig. 1. The Havel River downstream of the city Berlin with its major inflows (in bold). Labels for lakes and monitoring stations are used throughout the text for reference purposes.

(1999) and Schettler (1995) for a limited number of years and selected sites, no specific study on nitrogen retention has been available so far. The results give us an insight to which extent present nutrient concentrations of the Havel River are controlled by internal processes. We also describe how information on a key variable - the sediment phosphorus excess was derived from sampling data.

We then give an outline of the water quality simulation tool TRAM. After introducing the general philosophy of the program, we present the approaches that were used to account for nutrient retention and release in its application to the Havel River.

Finally, we present the results of scenario simulations with moderately reduced external loads of $\mathrm{N}$ and $\mathrm{P}$, which were conducted by coupling TRAM with mesoscale catchment models. After discussing limits of the model concept, the results of data analysis and modeling are summarized in the light of water quality management for the Lower Havel River.

\section{Study site}

The Lower Havel River downstream of Berlin (Fig. 1) is characterized by a number of large, interconnected shallow lakes (mean depth about $3.5 \mathrm{~m}$ ). Due to natural topography and river regulation the slope of the water surface is very low $(0.006 \%$ at $\mathrm{MQ})$. Even in river sections, flow velocities are very small and discharge can only be measure reliably by ultrasonic gages. The specific discharge of $4.61 \mathrm{~s}^{-1} \mathrm{~km}^{-2}$ at gauge Ketzin (label Hv0195 in Fig. 1) is low compared to other German river basins.

The Lower Havel River is currently classified as polytrophic. Although external nutrient loading decreased in the 1990s, the concentrations of phosphorus and nitrogen are still elevated (Fig. 2). In case of phosphorus, this is not only due to ongoing emissions from point and non-point sources but also due to internal loading. A large phosphorus pool has accumulated in the lakes' sediment over the past decades

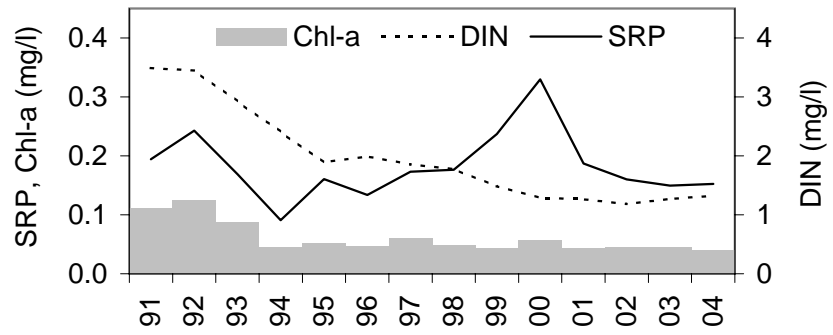

Fig. 2. Concentrations of dissolved phosphorus (SRP), dissolved inorganic nitrogen (DIN), and chlorophyll-a in the time period 19912004. Pooled data from 5 monitoring stations along the Potsdamer Havel.

(Rohde, 1995). Today, after partial reduction of external $\mathrm{P}$ loads, the excess phosphorus of the sediments is slowly released. The resulting delay in the recovery of water quality is a common phenomenon (Jeppesen et al., 1991; Kozerski and Kleeberg, 1998; Søndergaard et al., 2003).

\section{Methods}

\subsection{Quantification of nutrient retention}

To assess the retention of total phosphorus (TP) and total nitrogen $(\mathrm{TN})$ the results of water quality monitoring in the time period 1991-2004 were evaluated. Data were provided by the water authorities of Berlin and Brandenburg for 20 monitoring stations along the Lower Havel River (Fig. 1). The typical sampling interval is two weeks.

The seasonal dynamics of phosphorus retention was obtained from mass balances for the five largest lakes. Retention rates $r_{\mathrm{TP}}$ were calculated according to Eq. (1) by relating the observed phosphorus loads $\left(\mathrm{g} \mathrm{s}^{-1}\right)$ at lake outlet $\left(C_{\mathrm{TP} \text { out,obs }} \cdot Q\right)$ to simulated values $\left(C_{\mathrm{TP} \text { out,sim }} \cdot Q\right)$. The latter can be obtained from observed $\mathrm{P}$ loads in the lake's inflow $\left(C_{\mathrm{TP} \text { in,obs }} \cdot Q\right)$ if the lake is assumed to be a conservative stirred tank reactor (STR). The symbol $Q$ denotes the flow rate $\left(\mathrm{m}^{3} \mathrm{~s}^{-1}\right)$ and $V\left(\mathrm{~m}^{3}\right)$ is the lake volume. The difference between observed and simulated loads was then divided by the lake's surface area $A\left(\mathrm{~m}^{2}\right)$ and the time and mass units were converted to yield values of $r_{\mathrm{TP}}$ in $\left(\mathrm{mg} \mathrm{P} \mathrm{m}^{-2} \mathrm{~d}^{-1}\right)$. The underlying assumption of complete mixing is justified by the fact that the lakes are shallow and polymictic. Except for phases of calm weather in summer, stratification is prevented by wind.

$r_{\mathrm{TP}}=\frac{86.4 \cdot 10^{6} Q}{A} \times\left(C_{\mathrm{TP} \text { out }, \text { obs }}-C_{\mathrm{TP} \text { out }, \mathrm{sim}}\right)$

Negative values of $r_{\mathrm{TP}}$ indicate $\mathrm{P}$ retention whereas in times of net phosphorus release $r_{\mathrm{TP}}$ becomes greater than zero. Phosphorus retention in river and channel sections was neglected in this study, because the sediment surface area is small and residence time is short compared to that of the 
lakes. Also, we know from on site inspection that $\mathrm{P}$ enriched organic sediments rarely exist in the river and channel sections.

According to Jensen et al. (1992b) and Seitzinger (1988) nitrogen losses are mainly caused by two processes: denitrification and sedimentation. Both, nitrate reduction (Chapra, 1997) and settling of particulate N (Scheffer, 1998) can be described by first order kinetics. That is, the concentrations' rate of change depends linearily on the respective concentrations. Since Jensen et al. (1992b) found denitrification in lakes to be closer related to the concentration of $\mathrm{TN}$ rather than to $\mathrm{NO}_{3}^{-}$, a lumped first order term was tested for the description of total nitrogen retention (Eq. 2).

$$
-\frac{d C_{\mathrm{TN}}}{d t}=k_{\mathrm{TN}} \times C_{\mathrm{TN}}
$$

Estimates of the loss rate $k_{\mathrm{TN}}\left(\mathrm{d}^{-1}\right)$ for all major lakes shown in Fig. 1 were deduced from Eq. (3).

$k_{\mathrm{TN}}=\frac{86400 Q}{V} \times \frac{\left(C_{\mathrm{TN} \text { out }, \text { obs }}-C_{\mathrm{TN} \text { out }, \text { sim }}\right)}{C_{\mathrm{TN} \text { out }, \text { sim }}}$

In analogy to Eq. (1), $C_{\mathrm{TN} \text { out,obs }}$ is the observed concentration $\left(\mathrm{mg} \mathrm{l}^{-1}\right)$ at the lake outlet and $C_{\mathrm{TN} \text { outsim }}$ is the corresponding concentration that can be calculated from the TN load in the inflow if the lake is treated as a conservative stirred tank.

For river reaches between neighboring monitoring stations we estimated $k_{\mathrm{TN}}$ from the ratio of $\mathrm{TN}$ concentrations at these stations and the corresponding mean travel time of the water $T_{m}$ (d). The calculation is based on Eq. (4) which can easily be derived by integrating Eq. (2).

$k_{\mathrm{TN}}=\frac{1}{T_{m}} \times \ln \left(\frac{C_{\mathrm{TN}, \text { upstream }}}{C_{\mathrm{TN}, \text { downstream }}}\right)$

For calculating average values of $k_{\mathrm{TN}}$ for each month, monthly median values of the concentration ratio were used to account for outliers in the TN data. The corresponding mean travel times $T_{m}$ were determined by simulating the propagation of tracer pulses under steady flow conditions (i.e. $M Q_{\text {month }}$ ). Virtual tracer experiments were carried out with the program described in Sect. 3.3. In order to quantify the retention of nitrogen in the entire network shown in Fig. 1 we transfered $k_{\mathrm{TN}}$ values from neighboring reaches to those not covered by monitoring stations.

\subsection{Sediment analysis}

A reasonable prediction of water quality for the Havel River requires the future trend of phosphorus release from the lakes' sediments to be estimated. Doing so, it is a common practice to determine the $\mathrm{P}$ excess of the sediment at first. In a second step, the expected decline in the P excess over time is computed using observed rates of net phosphorus export. Whereas a constant export is assumed in simple estimations, more realistic results are obtained by relating the $\mathrm{P}$ export to the size of the P excess (Sect. 4.3).

The determination of the phosphorus excess in the sediment is a crucial step. A common method is to define a background concentration of phosphorus and to use the difference between the actual TP concentration and the background as an estimate of the P excess. Sas (1989) deduced from the analysis of several lake restoration programs a background value of $1.0 \mathrm{mg} \mathrm{P}(\mathrm{g} \mathrm{DW})^{-1}$. However, the transferability of this threshold value from one lake to another must be questioned as the $\mathrm{P}$ binding capacity of the sediment dry matter necessarily depends on its composition, e.g. the contents of $\mathrm{Fe}, \mathrm{Al}, \mathrm{Ca}$, or organic matter. In fact Nürnberg (1988) and Hupfer (1995) compared a number of lakes with different sediment TP and found only a slight or no significant relation with P release. Also Jensen et al. (1992a) concluded from a comparative study on shallow Danish lakes that the total P concentration is not an appropriate measure of the phosphorus release potential. Instead, they suggested that $\mathrm{P}$ release rates are related to the $\mathrm{Fe}: \mathrm{P}$ ratio in the upper sediment $(0-5$ $\mathrm{cm})$. However, the use of Fe:P ratios for estimating the total $\mathrm{P}$ excess of the sediment (including the anaerobic zone) is doubtful, as the high P sorption capacity of iron is bound to aerobic conditions (Pant and Reddy, 2001).

Although the total phosphorus concentration in the sediment was found to be unrelated to $P$ release when comparing different lakes, we think that the amount of TP above some background level is suitable for quantifying the $\mathrm{P}$ excess in a specific sediment sample (e.g. Kleeberg, 1995; Hupfer and Lewandowski, 2005).

Consequently, we analyzed sediment cores $(0-30 \mathrm{~cm}$ depth) at 8 locations of the lakes B-F (Fig. 1). The core samples were taken using an UWITEC corer with $6 \mathrm{~cm}$ diameter. The total concentration of phosphorus in core slices of $2 \mathrm{~cm}$ $(0-10 \mathrm{~cm}$ depth) and $4 \mathrm{~cm}($ depth $>10 \mathrm{~cm})$ was determined after digestion with $96 \% \mathrm{H}_{2} \mathrm{SO}_{4}$ at $450^{\circ} \mathrm{C}$ in presence of $\mathrm{H}_{2} \mathrm{O}_{2}$. The phosphate was determined photometrically after adjusting the $\mathrm{pH}$ to $3-4$ (molybdate method, $880 \mathrm{~nm}$ ). Additionally measured parameters include the dry weight, organic matter content (ignition loss after $2 \mathrm{~h}$ at $550^{\circ} \mathrm{C}$ ), total $\mathrm{Fe}$ and dissolved $\mathrm{P}$ in pore water. The pore water was obtained using mini-probes for direct suction sampling $(2 \mathrm{~mm}$ in diameter, $50 \mathrm{~mm}$ length). The sampled water was acidified at $\mathrm{pH} 2$ immediately after extraction to prevent co-precipitation of phosphate and iron.

\subsection{Outline of the water quality simulation tool TRAM}

\subsubsection{Representation of the river network}

In the simulation tool TRAM, the natural river system is represented as network of interlinked reactors. Two different types of reactors are currently available: stirred tanks (STR) and plug-flow reactors (PFR). Both concepts are commonly used in water quality modeling (e.g. Chapra, 1997; Reichert, 
1998). The fundamental property of a STR is complete mixing of the contained water. Thus, any transport of dissolved or suspended components through a STR is due to dispersive processes only. The stirred tank concept allows a reasonable approximation of matter transport in the shallow, polymictic lakes of the Lower Havel River. In contrast, the only transport mechanism in plug-flow reactors is advection. Any matter that enters a PFR at its upstream end is released at its downstream boundary with a time lag depending on flow velocity. The PFR concept is used for representing river and channel sections where advective transport is dominant. Obviously both concepts, STR and PFR, are limited in that only a single transport mechanism is considered. However, by connecting both types of reactors, advective-dispersive transport can be approximated.

The application of the reactor concept to a natural river network requires its subdivision into a number of PFR and STR. Special considerations are necessary when discretizing river or channel sections: Firstly, the geometry of a PFR is described by a single average cross-section. Therefore, irregularities in river morphology require a subdivision into several PFR. Secondly, the current version of TRAM expects the slope of the water surface within a plug-flow reactor to be negligible, since it was designed for lowland rivers. In the application to the Lower Havel River, a reasonable length of PFR is several hundred meters to about $1 \mathrm{~km}$, as water surface slopes do not exceed a few $\mathrm{cm} / \mathrm{km}$ due to topography and continuous impoundment. The system shown in Fig. 1 was subdivided into a number of 67 PFR and 21 STR.

The routing of matter through a system of interconnected PFR and STR requires information on the network hierarchy. Stream orders which constantly increase in the direction of flow must be assigned to all reactors to reflect the upstreamdownstream relations. As stream order computation is not straightforward for a large, looped network, a GIS utility was designed therefor. A bundle of additional GIS utilities handles the preprocessing of cross-section data for PFR as well as the derivation of storage curves for stirred tank reactors from bathymetry data.

\subsubsection{Hydrodynamics}

For solving the mass balance equation of a STR and for determining travel times in PFR, hydrographs of inflow and stage need to be known for all reactors. Because the simulation of hydrodynamics is not included in the TRAM program, an external software must be used. In the presented study, we chose the unsteady 1D hydrodynamic model HECRAS (USACE, 2002). It proved to be particularly suitable for it handles looped river networks and supports the import of geometric data via GIS. The RAS data base for the system shown in Fig. 1 includes about 1100 cross-sections and 27 junctions. Tributaries were represented as lateral inflows.

\subsubsection{Components and reactions}

At the current state of development the number of components which's fate can be modeled simultaneously with TRAM is virtually not limited. Also, there are hardly any restrictions with respect to the number and kind of considered reactions. This flexibility is enabled by the fact that the declaration of components as well as the description of their kinetics and stoichiometry is not a static part of the source code. Instead, the user provides an ordinary differential equation (ODE) for each process and each component to be simulated. Each of the ODE describes the influence of the process on the derivative of a component's concentration with respect to time. In contrast to other modeling tools (e.g. Reichert, 1998), the system of ODE is written to a plain textfile using a simple markup language. The ODE system is then parsed by a preprocessor and automatically translated into several FORTRAN 95 source files. After recompiling TRAM with the generated "dynamic sources" it is prepared for the specific water quality problem at hand.

Four different types of variables can be reference in an ODE to describe a component's kinetics: component concentrations, constants, boundary condition variables and hydraulic variables. Whereas the user is free to declare as many constants (i.e. decay rates) and boundary condition variables (e.g. time series of external loads) as needed, the set of available hydraulic variables is reactor dependent. It includes the reactor volume and the surface area of water and sediment in case of STR and wet perimeter, top width, hydraulic depth and flow velocity in case of PFR. Components are further distinguished into mobile (those transported with the flow) and immobile ones (sediment concentrations). While immobile components can already be simulated in STR the implementation for plug-flow reactors is still incomplete.

The actual ODE system we used to account for the retention of $\mathrm{P}$ and $\mathrm{N}$ in the Havel River is given in Sect. 4.3 as it must not be seen independent from the results of sediment analysis (Sect. 4.2). It is presented in form of the "process matrix" as suggested by Reichert (1998) and Reichert et al. (2001).

\subsubsection{Computation algorithm}

In contrast to many spatial simulation models the presented program does not update the simulated variables after each time step in the entire model domain. Instead, transport and reactions in a single reactor are always simulated over the full time period. After the hydrographs of output load for all mobile components from a reactor have been computed, the algorithm proceeds with another reactor of equal or higher stream order. Within a complete model run, the computation advances from the most upstream reactor(s) of the river network to the downstream model boundary. The obvious drawback of this time and memory efficient algorithm is that flow reversal cannot be handled. 


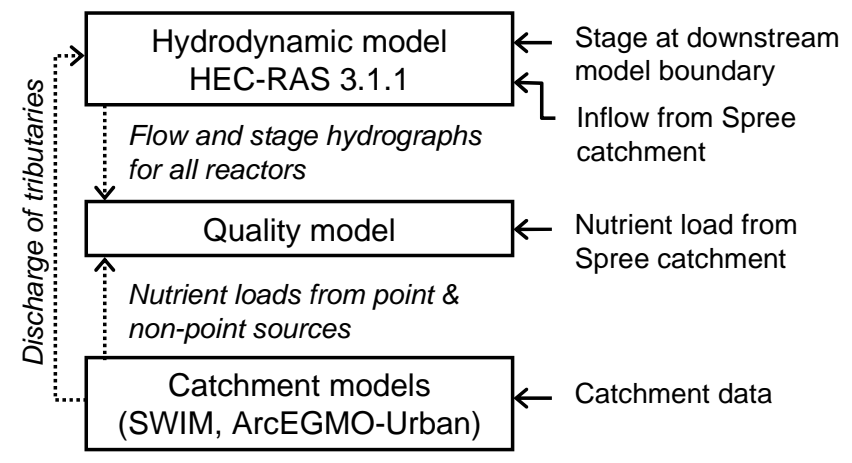

Fig. 3. Interaction between the water quality model with the hydrodynamic and catchment model(s). Dotted arrows indicate the exchange of boundary conditions while solid arrows mark external input data.

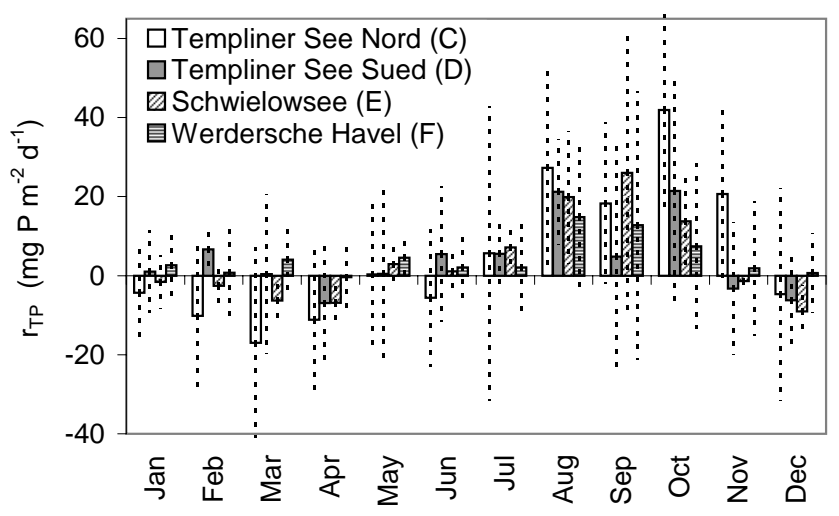

Fig. 4. Monthly medians of net phosphorus export (positive) and retention (negative) for 4 large lakes of the Lower Havel River over the period 1995-2000 (see Fig. 1 for the lakes' locations). The 95\% confidence interval is indicated by dotted lines.

For generating output load hydrographs of a reactor, the change of the components' concentrations over time needs to be monitored. In case of STR which are characterized by spatial homogeneity this is equal to continuously solving the reactor's mass balance equation. In case of PFR, the program must keep track of the change in concentrations in separate control volumes as they travel downstream through the reactor. Anyway, numerical integration of the (usually coupled) system of ODE which is essentially described by the process matrix and the transport terms is necessary. The system's general structure is shown in Eqs. (5-6) with $n$ being the number of involved processes and $m$ being the number of components. Note that the transport term which includes the input load $L\left(\mathrm{~g} \mathrm{~s}^{-1}\right)$, the inflow rate $Q\left(\mathrm{~m}^{3} \mathrm{~s}^{-1}\right)$, and the reactor volume $V\left(\mathrm{~m}^{3}\right)$ is evaluated for STR and mobile components only. The sum term, which corresponds to one column of the process matrix (see Table 3 for an example) integrates the effect of all transformational processes.

$$
\begin{aligned}
& \frac{d C_{1}}{d t}=\frac{L_{1}-C_{1} \times Q}{V}+\sum_{p=1}^{n} \frac{d C_{1, \mathrm{p}}}{d t} \\
& \cdots \\
& \cdots \\
& \frac{d C_{\mathrm{m}}}{d t}=\frac{L_{\mathrm{m}}-C_{\mathrm{m}} \times Q}{V}+\sum_{p=1}^{n} \frac{d C_{\mathrm{m}, \mathrm{p}}}{d t}
\end{aligned}
$$

Two alternative integrators are implemented in TRAM: A variable step size 5th-order Runge-Kutta scheme and a Rosenbrock algorithm for coping with stiff ODE systems. Both solvers were adapted from Press et al. (2002).

\subsection{Integration of water quality and catchment models}

In addition to flow hydrographs, time series of river loads for all simulated components must be known at the upstream boundaries of the TRAM model domain. For simulation of present conditions (model validation) data were available from the water authorities. However, in case of the scenario analyses presented in Sect. 4.5 simulated boundary conditions had to be used. TP and TN loads as well as discharges that enter the system shown in Fig. 1 were calculated by a catchment modeling work group using the models SWIM (Krysanova et al., 2000) and ArcEGMO-Urban (Biegel et al., 2005). SWIM computes the discharge of tributaries and the corresponding $\mathrm{P}$ and $\mathrm{N}$ loads resulting from non-point emissions. In contrast, the Urban module of ArcEGMO simulates $\mathrm{N}$ and $\mathrm{P}$ inputs from point sources. Discharge and nutrient loads of the tributary Spree were approximated based on observed flow and concentration data also for scenario simulations. The interaction between TRAM and the applied catchment models is illustrated in Fig. 3.

\section{Results}

\subsection{Observed patterns of phosphorus and nitrogen retention}

The seasonal dynamics of the phosphorus retention rate as it was calculated using Eq. (1) is shown in Fig. 4. A phenomenon observed in all investigated lakes is a period of sediment phosphorus release from July-November with maximum rates in late summer. Actually, the term "net release" should be used as $r_{\mathrm{TP}}$ integrates three major processes: The settling of particulate organic $\mathrm{P}$, the release of mineralized $\mathrm{P}$ from freshly settled degradable organic matter, and the release of excess $\mathrm{P}$ which has accumulated in the past period of higher external loading. In winter and spring $r_{\mathrm{TP}}$ is near zero, which - as settling of organic $\mathrm{P}$ is low - shows that phosphorus release is negligible. Slightly negative values occur in some lakes in spring, indicating that not all of the settling $\mathrm{P}$ is instantaneously recycled during this season. We 


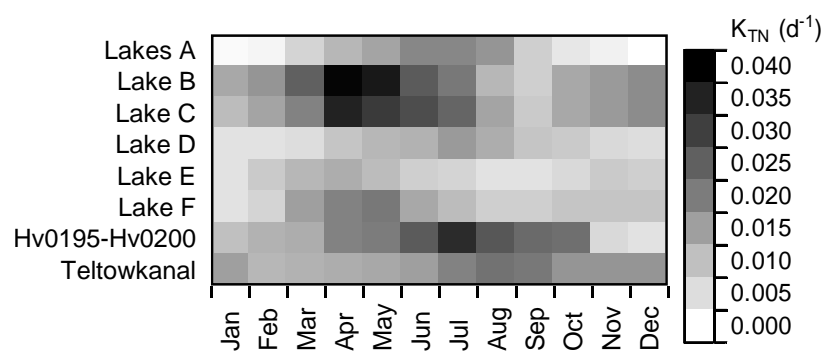

Fig. 5. Estimates of the rate constant $k_{\mathrm{TN}}\left(\mathrm{d}^{-1}\right)$ used for approximating the retention of total nitrogen by a first order kinetics. The values were identified in the time period 1995-2000. Refer to Fig. 1 for labels.
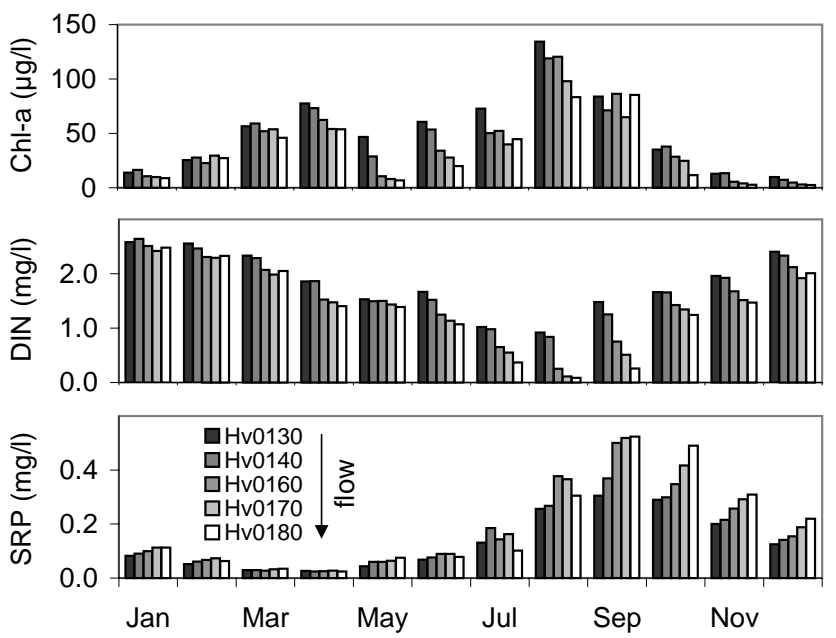

Fig. 6. Average seasonality in the concentrations of dissolved phosphorus (SRP), dissolved inorganic nitrogen (DIN), and chlorophylla at five successive monitoring stations along the Potsdamer Havel (monthly medians of the time period 1996-2002). See Fig. 1 for the locations.

found analogous seasonal patterns also for a river-lake system in the nearby Nieplitz catchment. Comparable patterns and magnitudes of net phosphorus release are reported from Danish lakes (Søndergaard et al., 2002). As Fig. 4 illustrates, $r_{\mathrm{TP}}$ is greater than zero when averaged over the whole year. This fact clearly indicates that the lakes currently undergo a phase of recovery by sediment $\mathrm{P}$ loss.

The released phosphorus accumulates in the direction of flow. While the average TP concentration (July-October) in lake $\mathrm{C}$ is $0.42 \mathrm{mg} \mathrm{l}^{-1}$ it increases to $0.55 \mathrm{mg} \mathrm{l}^{-1}$ in lake F. This is also reflected by the concentrations of dissolved phosphorus (SRP) as can be seen in Fig. 6.

Since we did not differentiate the processes involved in total nitrogen loss (Sect. 3.1), the determined values of the retention parameter $k_{\mathrm{TN}}$ integrate both, denitrification and $\mathrm{N}$ sedimentation. As Fig. 5 illustrates, nitrogen retention is low in winter with $k_{\mathrm{TN}}$ in the range $0-0.02 \mathrm{~d}^{-1}$. In summer $\mathrm{N}$ losses range from $0.005-0.03 \mathrm{~d}^{-1}$ in most sections of the

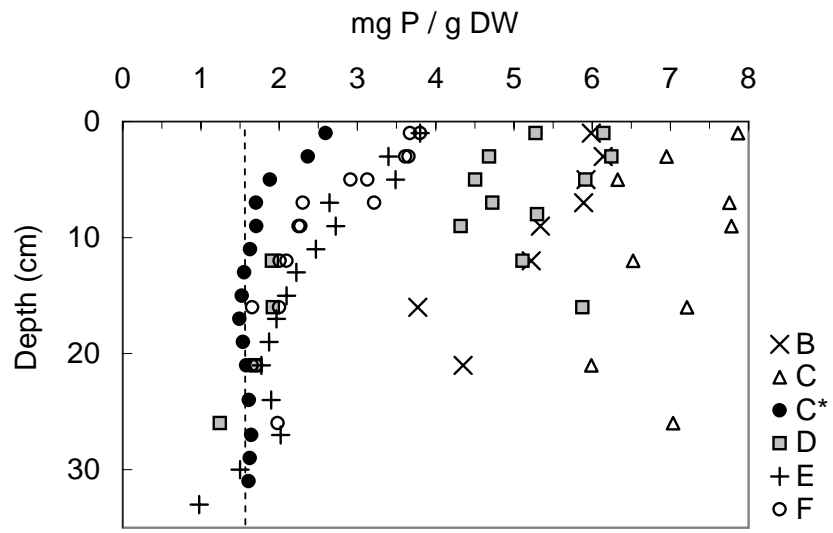

Fig. 7. Vertical profiles of total phosphorus in the upper sediment of the sampled Havel Lakes B-F (see Fig. 1). Profile $C^{*}$ refers to an isolated bay of lake $\mathrm{C}$. The dashed line marks the base concentration of $1.5 \mathrm{mg} \mathrm{P}(\mathrm{g} \mathrm{DW})^{-1}$ which is used in the estimation of the $\mathrm{P}$ excess.

river-lake cascade. Maximum values of about $0.04 \mathrm{~d}^{-1}$ indicate that up to $4 \%$ of total nitrogen may be eliminated in one day. The seasonality of nitrogen losses and its effect on the concentration of dissolved inorganic nitrogen (DIN) at successive monitoring stations is partially reflected by Fig. 6 .

Figure 5 shows conspicuous differences in magnitude and seasonality of TN retention between water bodies in terms of $k_{\mathrm{TN}}$. A satisfying explanation of the observed patterns would require more detailed investigations that do not focus on total nitrogen alone. However, some first hypothesis are given in Sect. 5.1. The absolute values of TN retention in the shallow lakes (Table 1) are comparable to those reported from a study in Denmark (Windolf et al., 1996).

\subsection{Results of sediment analysis}

Figure 7 presents sediment profiles of total phosphorus that were constructed from core samples of the Potsdamer Havel Lakes. Very high concentrations of TP were found in the sediments of lake B and C. This was expected, as these lakes are nearest to the main sources of phosphorus pollution, the mouth of the Teltowkanal and the Spree River which receive treated sewage from the Berlin metropolitan area. While the TP concentration shows some decline with increasing sediment depth, no convergence to a base value was found within the sampled layer of $30 \mathrm{~cm}$ thickness. A different picture shows up in the lakes D, E, and F, which are located further downstream along the Potsdamer Havel. While increased $\mathrm{P}$ levels were identified in the upper part of the profile, the concentration seems to approach a threshold level with increasing sediment depth. From the small number of data, we pragmatically estimated a threshold level of $1.5 \mathrm{mg} \mathrm{P}(\mathrm{g} \mathrm{DW})^{-1}$ (dashed line in Fig. 7). Relating this TP content to measured concentrations of total iron yields an atomic Fe:P ratio of 1317 at the sediment surface. This ratio should be high enough 
Table 1. Monthly median values of TN retention $\left(\mathrm{mg} \mathrm{m}^{-2} \mathrm{~d}^{-1}\right)$ for lakes of the Potsdamer Havel calculated from mass balances for the years 1996-2002. See Fig. 1 for lake labels C-F.

\begin{tabular}{lrrrrrrrrrrrr}
\hline Lake & Jan & Feb & March & April & May & June & July & Aug & Sep & Oct & Nov & Dec \\
\hline C & 107 & 141 & 322 & 330 & 230 & 227 & 224 & 181 & 184 & 140 & 168 & 124 \\
D & 43 & 124 & 71 & -15 & 36 & 42 & 133 & 44 & 27 & 46 & 16 & -13 \\
E & 42 & 100 & 161 & 137 & 67 & 35 & 27 & 20 & 51 & 75 & 67 & 44 \\
F & 48 & 57 & 97 & 148 & 80 & 72 & 37 & 71 & -8 & 90 & 66 & 20 \\
\hline
\end{tabular}

Table 2. Calculated phosphorus excess $P X$ in the top $30 \mathrm{~cm}$ of sediment of the Havel Lakes B-C (see Fig. 1).

\begin{tabular}{lrrrrr}
\hline Lake & B & C & D & E & F \\
PX $\left(\mathrm{g} \mathrm{P} \mathrm{m}^{-2}\right)$ & 234 & 178 & 84 & 55 & 21 \\
\hline
\end{tabular}

to reduce the phosphorus release potential noticeably according to Jensen et al. (1992a).

The sediment phosphorus excess PX was calculated for each core and each layer as the difference between the actual TP concentration and the estimated base level of 1.5 $\mathrm{mg} \mathrm{P}(\mathrm{g} \mathrm{DW})^{-1}$. The surplus phosphorus of all layers was summed for each core and data were averaged where multiple samples from a single lake were available. The obtained values of PX $\left(\mathrm{g} \mathrm{P} \mathrm{m}^{-2}\right)$ are summarized in Table 2 . The value for lake B was also applied to lake A where no core samples were taken so far.

As Fig. 7 reveals, the assessment of the total phosphorus excess in the highly contaminated lakes B and C would require core samples of more than $30 \mathrm{~cm}$ length to be analyzed. However, for the desired short term predictions the insufficient sampling depth is a less severe problem. If we relate the observed average annual phosphorus export rate of lake $\mathrm{C}$ (4 $\mathrm{g} \mathrm{P} \mathrm{m}^{-2} \mathrm{a}^{-1}$, years 1996-2004) to the estimated $\mathrm{P}$ excess of the upper sediment (see Table 2) the expected depletion in PX is only about $11 \%$ after 5 years and $20 \%$ after 10 years. The same changes would apply to the rate of $\mathrm{P}$ release if a linear dependence on the sedimentory $\mathrm{P}$ excess is assumed. For the time being, we accept this uncertainty but an analysis of deeper sediment layers is absolutely necessary if long term predictions are to be made.

\subsection{Representation of $\mathrm{P}$ release and $\mathrm{N}$ retention in the water quality model}

Based on Sect. 4.1 and 4.2 we now derive the equations that were used by TRAM to account for the retention and release of nutrients in the Lower Havel River. In case of nitrogen retention we simply keep to the concept of a first order loss process as described in Sect. 3.1. Thus the empirically determined constant $k_{\mathrm{TN}}$ is the only model parameter affecting the TN concentration. In contrast, the phosphorus part of the

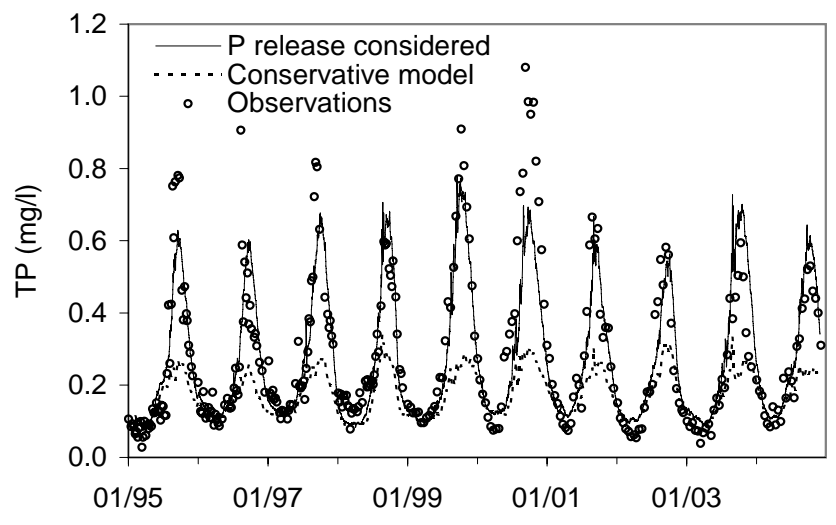

Fig. 8. Observed and simulated TP concentration of the Havel River at monitoring station Hv0195 downstream of the Havel Lakes.

model is subject to a number of fundamental assumptions.

First of all it is supposed that, in the present phase of sediment recovery, no permanent accumulation of settling phosphorus takes place. That is, all fresh organic phosphorus which is transfered to the sediment is assumed to undergo fast recycling. Though a $100 \%$ recycling rate is somewhat unlikely to occur in nature, there are indications that a large part of settled organic $\mathrm{P}$ is mineralized within short times. Hupfer and Gächter (1995) found that $70 \%$ of settled P is lost from the sediment of the stratified Lake Sempach during early diagenesis. For the deep Lake Arendsee Hupfer and Lewandowski (2005) estimated that about $60 \%$ of settled $\mathrm{P}$ is recycled within two weeks and a fraction of only $10 \%$ was found to be subject to long term storage. In the polymictic Havel Lakes an efficient recycling of organic matter is likely due to the aerobic conditions. The advantage of this assumption is obvious: Since settling of organic P and mineralization equate to zero, we can neglect the distinction between the observed net $\mathrm{P}$ release rate of the sediment and the gross release rate, which is due to the decay of the sedimentary $\mathrm{P}$ excess PX. Thus, we can directly use $r_{\mathrm{TP}}$ (Sect. 4.1) to calculate the change in PX.

Secondly, we consider the decay of the sediment phosphorus excess as a first order process, i.e. the rate of $\mathrm{P}$ release is presumed to decrease proportional to the decline in PX. This implies that the release rate is independent from the concentration of dissolved phosphorus in the overlying water. We 
Table 3. Process matrix for the simulation of TP and TN concentrations in a STR. The differential equation which describes the change in the concentration of a component (columns headers) due to a single process (row headers) is obtained by multiplying the corresponding process rate (rightmost column) with the stoichiometry coefficient (matrix element in the relevant column and row). See Reichert et al. (2001) for an introduction to the matrix notation.

\begin{tabular}{l|ccc|r}
\hline Process & $\begin{array}{c}\mathrm{TP} \\
\left(\mathrm{g} \mathrm{m}^{-3}\right)\end{array}$ & $\begin{array}{c}\mathrm{PX} \\
\left(\mathrm{g} \mathrm{m}^{-2}\right)\end{array}$ & $\begin{array}{c}\mathrm{TN} \\
\left(\mathrm{g} \mathrm{m}^{-3}\right)\end{array}$ & Process rate \\
\hline $\begin{array}{l}\text { P release } \\
\text { N retention }\end{array}$ & $A / V$ & -1 & 0 & Eq. (7) \\
\hline
\end{tabular}

emphasize that this assumption is bound to a phosphate concentration in the sediment pore water which is much higher than the pelagic SRP concentration. Only then the diffusive flux rate is insensitive to changes in the pelagic SRP.

Finally, we assume that the seasonal pattern of $\mathrm{P}$ release remains unchanged while the absolute $P$ release rate declines as PX becomes smaller. The rationale behind this is that mineralization activity - and thus $\mathrm{P}$ release from redox-sensitive and organic binding forms - are basically bound to the seasonal cycle of temperature.

Due to the above mentioned simplifications, we come up with the simple $3 \times 2$ process matrix shown in Table 3 . It includes two processes ( $\mathrm{P}$ release, $\mathrm{N}$ retention) and three components: TP, TN and the sediment phosphorus excess PX. Note that $\mathrm{P}$ release is considered for reactors of type STR only as it was found to be much less relevant in river sections.

$$
\begin{aligned}
& C_{\mathrm{PX}} \times f \times \frac{r_{\mathrm{TP}, \text { init }}}{C_{\mathrm{PX}, \text { init }}} \\
& k_{\mathrm{TN}} \times C_{\mathrm{TN}}
\end{aligned}
$$

In the process rate of $\mathrm{P}$ release (Eq. 7) the symbol $C_{\mathrm{PX}}$ denotes the current phosphorus excess in the considered sediment layer $\left(\mathrm{g} \mathrm{P} \mathrm{m}^{-2}\right)$ and $C_{\mathrm{PX} \text {, init represents the phospho- }}$ rus excess at the beginning of the simulation period. $r_{\mathrm{TP}}$,init $\left(\mathrm{g} \mathrm{P} \mathrm{m}^{-2} \mathrm{~s}^{-1}\right)$ is the phosphorus release rate corresponding to $C_{\mathrm{PX}}$,init at the time of the year when releases is highest. The dimensionless scaling factor $f$ accounts for the observed seasonal pattern of $\mathrm{P}$ release. While $f$ is zero in spring it approaches unity in late September when maximum release rates occur. Furthermore, in Table $3, A\left(\mathrm{~m}^{2}\right)$ is the surface area of the sediment and $V\left(\mathrm{~m}^{3}\right)$ is the volume of water in the STR. In the process rate of $N$ retention (Eq. 8) $C_{\mathrm{TN}}$ is the total nitrogen concentration and $k_{\mathrm{TN}}$ is the first order rate constant introduced in Sect. 3.1. Note that the transport terms which account for changes in the concentrations of TP and TN due to the reactor's inflow and outflow are not included in the process rates (Eqs. 7 and 8). These terms are appended by the simulation program automatically in case of mobile components.
Table 4. Errors in simulated TP and TN concentrations at monitoring station Hv0195 (see Fig. 1) in the time period 1995-2004. The retention parameters $r_{\mathrm{TP}}$ and $k_{\mathrm{TN}}$ were estimated in the years 19952000. ME: mean error $\left(\mathrm{mg} \mathrm{l}^{-1}\right)$, MAPE: mean absolute percental error (\%), NSI: Nash/Sutcliffe index (-).

\begin{tabular}{clrrrrr}
\hline Variable & & $95-96$ & $97-98$ & $99-00$ & $01-02$ & $03-04$ \\
\hline TP & ME & 0.00 & -0.02 & -0.08 & 0.00 & 0.05 \\
& MAPE & 28.0 & 21.0 & 22.0 & 27.0 & 29.0 \\
& NSI & 0.63 & 0.81 & 0.75 & 0.83 & 0.70 \\
TN & ME & 0.05 & -0.09 & 0.23 & 0.11 & 0.10 \\
& MAPE & 23.0 & 17.0 & 19.0 & 16.0 & 18.0 \\
& NSI & 0.02 & 0.05 & 0.29 & 0.45 & 0.67 \\
\hline
\end{tabular}

\subsection{Model test}

Before running any scenario simulations, we tested the model's performance in the time period 1995-2004 (Fig. 8, Table 4). The parameters $r_{\mathrm{TP}}$ and $k_{\mathrm{TN}}$ were estimated in 1995-2000 as described in Sect. 3.1 with some further calibration in case of $\mathrm{N}$. The sediment phosphorus excess in 1995 was counted back using information on the present values (Table 2) and the observed $\mathrm{P}$ export in the past. Thus, 1995-2000 should be regarded as the calibration period while the years 2001-2004 can be referred to as the validation period.

By comparing simulated concentrations of TP and TN to observation data we could demonstrate the usefulness of the followed transport calculation approach. By looking at simulated concentrations in winter, when $\mathrm{N}$ retention and $P$ release are less significant, we could also verify that the system's most relevant boundary conditions have been accounted for. Finally, by comparing the results to a simulation with nutrient retention/remobilization being neglected (conservative model run) we could demonstrate how much the transfer of nutrients to downstream reaches is affected by turnover in the studied river section.

Summer phosphorus concentrations predicted by the conservative model (dashed graph in Fig. 8) deviate from the simulation results with consideration of $\mathrm{P}$ release (solid line) by a factor of $2-3$. We can conclude that current $\mathrm{P}$ concentrations are increased by this factor compared to a situation where net $\mathrm{P}$ release is zero. This clearly has a negative impact on downstream waters including several other lakes that suffer from eutrophication. It should be noted that the P concentrations predicted by the conservative model correspond to a sediment $\mathrm{P}$ excess which has dropped to zero, provided that all settling $\mathrm{P}$ is instantaneously mineralized. In case of incomplete recycling of settled organic matter, the expected $P$ concentrations would be even lower.

The variation of the simulation error from year to year (Fig. 8) indicates that the phosphorus release from lake sediments is actually quite variable. We will discuss this interannual variability of $r_{\mathrm{TP}}$ in Sect. 5.1. 


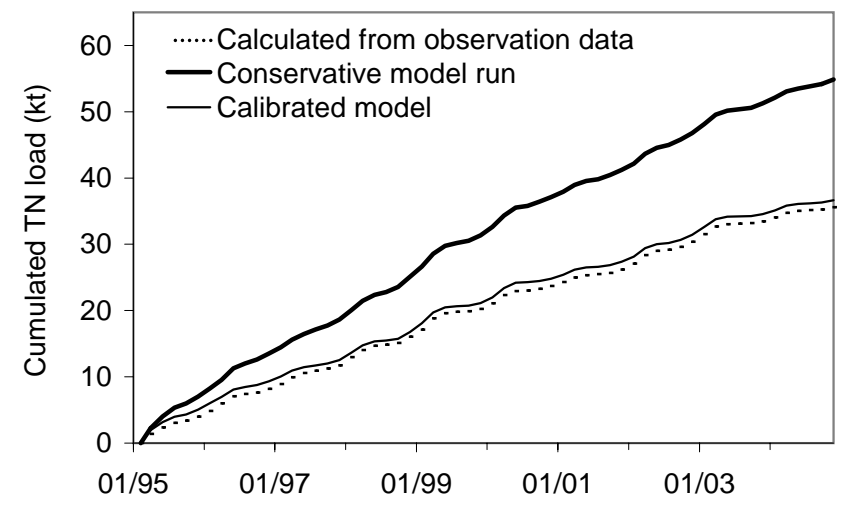

Fig. 9. Cumulated load of total nitrogen (kilotons) at the downstream end of the river network (monitoring station Hv0200 in Fig. 1) as computed from observed data and model simulations.

A simple way to figure out total nitrogen retention quantitatively is to compare cumulated $\mathrm{N}$ loads calculated by the model with and without consideration of $\mathrm{N}$ loss. From Fig. 9 it can be deduced that about $30 \%$ of the total nitrogen which is discharged into the studied river section via its tributaries is retained. This results in a significant reduction of $\mathrm{N}$ export to downstream waters. Compared to estimated in-stream nitrogen retention in a Danish lowland river (Svendsen et al., 1998) nitrogen losses in the Havel River are remarkably high. Since denitrification is most effective at the sediment-water interface (Seitzinger, 1988), this might be explained to a substantial extend by the large surface area of the Havel Lakes (see also Behrendt and Opitz, 2000).

Figure 9 also illustrates that the deviation between model simulation and observation is rather small when looking at cumulated TN loads. However, as Table 4 shows the temporal variability in $\mathrm{TN}$ concentrations is replicated by the model less accurately.

\subsection{Scenario simulations}

The results of two selected scenarios which account for measures to control phosphorus emissions are presented here. In the first scenario ("P1") it was assumed that phosphorus emissions from point sources were diminished all over the Havel basin except for the subbasin of the tributary Spree, which was not in the focus of the study (Table 5). Considered actions include the completion of all sewage treatment plants being in construction as well as upgrades in $\mathrm{P}$ elimination techniques to the highest standards in plants of all size. Furthermore it was assumed that the wastewater of households which are currently unconnected to a sewer system is treated in small scale sewage works. The corresponding reduction in $\mathrm{P}$ emissions was estimated with the ArcEGMO-Urban model (Biegel et al., 2005). The second scenario ("P2") includes scenario P1 but comes with the additional assumption that the average $\mathrm{P}$ load emitted from the
Table 5. Assumed reduction of TP emissions from the Spree catchment $\left(E_{\text {Spree }}\right)$ and all other subcatchments $\left(E_{\text {Other }}\right)$ and its effect on the modeled average TP concentration of the Havel River $C_{\mathrm{Havel}}$ at monitoring station Hv0200 (see Fig. 1). The initial values for the base scenario $\mathrm{P} 0$ are averages over 13 years.

\begin{tabular}{|c|c|c|c|c|}
\hline $\begin{array}{l}\text { Scenario } \\
\text { P0 }\end{array}$ & $\begin{array}{l}E_{\text {Spree }} \\
6.2 \mathrm{~g} / \mathrm{s}\end{array}$ & $\begin{array}{l}E_{\mathrm{Other}} \\
4.2 \mathrm{~g} / \mathrm{s}\end{array}$ & $\begin{array}{r}E_{\text {Total }} \\
10.4 \mathrm{~g} / \mathrm{s}\end{array}$ & $\begin{array}{r}C_{\text {Havel }} \\
0.23 \mathrm{mg} / 1\end{array}$ \\
\hline & $\Delta E_{\text {Spree }}$ & $\Delta E_{\text {Other }}$ & $\Delta E_{\text {Total }}$ & $\Delta C_{\text {Havel }}$ \\
\hline $\mathrm{P} 2$ & $-50.0 \%$ & $-13.0 \%$ & $-35.2 \%$ & $-25.4 \%$ \\
\hline
\end{tabular}

Spree catchment - which includes the Berlin metropolitan area - is reduced by approximately $50 \%$ to reach an average concentration of about $80 \mu \mathrm{g} \mathrm{l}^{-1}$. This target concentration was proposed by a wastewater management plan (Senat, 2001). The base scenario with unchanged $P$ emissions was called "P0". All simulations were carried out for a period of 13 years with initial conditions corresponding to 2003. This period was chosen in order to account for climate variability and to allow the potential situation in the year 2015 to be assessed, which is a milestone in the implementation of the EU-WFD. Meteorological boundary conditions for the catchment models were taken from the time period 1988-2000.

The effects of the pollution control measures are presented in Table 5. As indicated by the average emissions $\left(\mathrm{g} \mathrm{s}^{-1}\right)$ for the base scenario P0, the Spree catchment alone contributes over $50 \%$ of the total P input to the Lower Havel River. Consequently, the reduction of $\mathrm{P}$ emissions from all other subcatchments by about $13 \%$ (scenario P1) can have only little effect on the total P input $(-5.2 \%)$. On the other hand, a $50 \%$ decrease in P loads of the Spree River and its side branch, the Teltowkanal, results in a significant change in total $\mathrm{P}$ input $(-35.2 \%)$. According to the model, the alteration in the average TP concentration of the Havel River $\Delta C_{\text {Havel }}$ is by a factor of ca. 0.7 smaller than the change in total emissions $\Delta E_{\text {Total }}$. Internal phosphorus loading is responsible for this.

In Fig. 10 the results of the scenario analysis are presented in form of average $\mathrm{P}$ concentrations for the 13 simulated years. In this figure, a fourth scenario (P0*) has been added which is identical to scenario $\mathrm{P} 0$ with respect to external phosphorus loading. But in contrast to $\mathrm{P} 0$ the decline in the sedimentary $\mathrm{P}$ excess was neglected in scenario $\mathrm{P} 0 *$, i.e. a continued $\mathrm{P}$ release at the present level was assumed. A comparison of the graphs $\mathrm{P} 0, \mathrm{P} 0 *$, and $\mathrm{P} 2$ suggests that the drop in the average $\mathrm{P}$ concentration due to the fading $\mathrm{P}$ release is almost comparable to the drop that could be achieved by implementing the measures associated with scenario P2 after a period of 13 years. A look on the calculated change in the sediment phosphorus excess reveals a depletion of remarkable 62 and $80 \%$ in lake $E$ and $F$ within the simulation period. The corresponding change in $\mathrm{PX}$ in the higher polluted lakes B, C, and D amounts to 20,32 , and $35 \%$, respectively. 


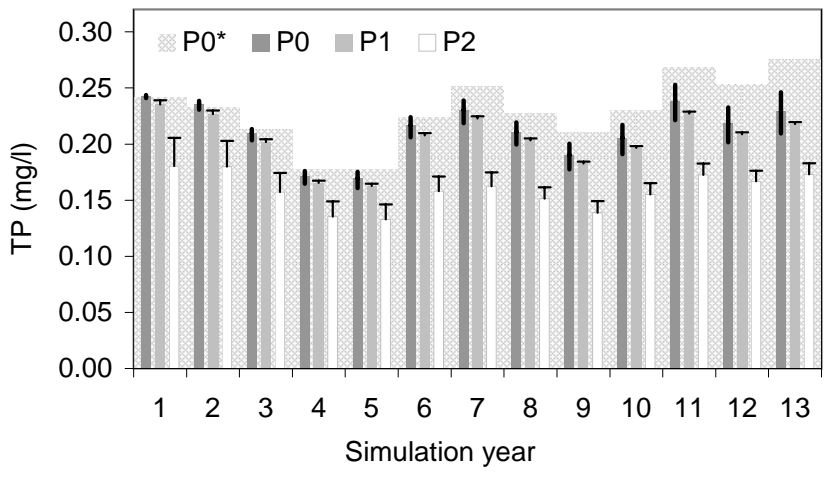

Fig. 10. Simulated average TP concentrations at monitoring station $\mathrm{Hv} 0200$ for the scenarios with altered phosphorus emissions P1 and $\mathrm{P} 2$, compared to the status-quo scenario $\mathrm{P} 0$. The scenario $\mathrm{P} 0^{*}$ was derived from $\mathrm{P} 0$ by leaving the decline in the sediment $\mathrm{P}$ excess (PX) unconsidered. The bold two-sided error bars indicate the sensitivity of results for scenario $\mathrm{P} 0$ with respect to the initial values of PX (initial PX altered by $\pm 100 \%$ ). The T-shaped bars extending the columns for scenario P1 and P2 illustrate how the predicted concentrations would change, if the magnitude of internal loading would increase proportional to the reduction of external P loads.

The fact that Fig. 10 shows stagnating or even increasing $\mathrm{P}$ concentrations rather than the expected decrease is attributed to the time series of meteorological conditions, which underly the scenario simulations (declining discharge). While this may be confusing at the first glance, it demonstrates the strong influence of the variability in runoff on the nutrient concentrations of the Havel River.

The seasonality of the simulated TP concentrations for the scenarios P0, P1, and P2 is illustrated in Fig. 11. One should keep in mind that the general seasonal pattern of internal $P$ loading was assumed to be unaffected by the reduction in external P loads (Sect. 4.3). As in Fig. 10, the graph labeled P0* demonstrates how the results for scenario P0 would change if the decrease in internal $\mathrm{P}$ loading due to the decline in the sediment phosphorus excess was neglected.

As with phosphorus, different cases of reduced nitrogen emissions were analyzed but we present only a single scenario here. Contrary to the $\mathrm{P}$ scenarios, the potential for further enhancement of $\mathrm{N}$-elimination in sewage treatment was considered to be insignificant. The officially reported grades of purification are very high already. Thus, the scenario ("N1") assumed that only non-point nitrogen emissions were reduced all over the Havel basin, again excluding the Spree subbasin. To simulate this, digital maps of present landuse were reclassified (Jacobs and Jessel, 2003) to reflect a partly conversion of arable land to grassland and fallow as well as the growing of intercrops to minimize $\mathrm{N}$ losses. The expected change in $\mathrm{N}$ export from the catchment due to the assumed changes in landuse was calculated by project partners using the SWIM model. According to simulation results, the average nitrogen export from the considered sub-

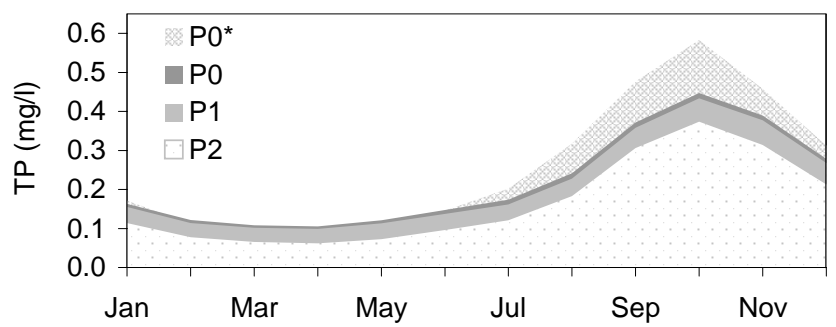

Fig. 11. Simulated seasonality of the TP concentration at monitoring station $\mathrm{Hv0200}$ for the scenarios with altered phosphorus emissions (monthly averages over the final four years of the 13-year simulation period).

basins could be reduced by about $29 \%$ if all the suggested management measures were implemented. The predicted average TN concentration at the downstream boundary of the studied river section (station Hv0200) changes from 1.72 to $1.57 \mathrm{mg} \mathrm{N}^{-1}$ (-9\%) according to water quality simulations. This figure must not be underrated as only about $40 \%$ of the total catchment area were affected by the suggested measures of emission control. Certainly, a more significant drop in nitrogen concentrations could be achieved if an equivalent reduction in N emissions would take place in the Spree catchment too.

The sensitivity of simulation results to changes in the retention parameter $k_{\mathrm{TN}}$ is expressed by the following figures: If the rate constant is varied by $\pm 50 \%$, the computed average $\mathrm{TN}$ concentration at station $\mathrm{Hv} 0200$ changes by $-14 \%$ and $+18 \%$, respectively. As nitrogen retention is higher in summer, the same applies to the sensivity of simulation results. E.g. the corresponding changes in July amount to -25 and $+35 \%$, if the absolute values of $k_{\mathrm{TN}}$ are increased or lowered by $50 \%$, respectively. These figures again demonstrate the importance of nitrogen losses in the studied section of the Havel River.

\section{Discussion}

5.1 Significance and variability of nutrient retention in the Lower Havel River

The net phosphorus release rates shown in Fig. 4 result in a significant increase of pelagic $\mathrm{P}$ concentrations in the second half of the year. Therefore, at present, phosphorus limitation of primary production does not occur during summer. Instead, the underwater light climate (self-shading) is assumed to be the major limiting factor for primary production, possibly accompanied by temporary nitrogen shortage.

The differences between observed and simulated TP concentrations (Fig. 8) indicate that the magnitude of net phosphorus release from sediments is not the same each year. Certainly, multiple causes must be considered. We presume that variability in the seasonal succession of plankton might be 
of great importance. E.g. increased settling of algal biomass could favor the release of iron bound $\mathrm{P}$ by causing a drop in the redox potential owing to raised mineralization activity at the sediment surface. However, higher sedimentation of organic $\mathrm{P}$ could also result in lower net phosphorus release if the decomposition capacity is exceeded and $\mathrm{P}$ recycling is therefore delayed.

In addition to biological processes, physical factors must be taken into account. E.g. short periods of temporary stratification may occur in some years even in shallow lakes in times of high temperatures and low wind action. Those events can hardly be predicted but they may have a considerable impact on the redox status of the sediment surface and thus on P release (Welch and Cooke, 2005; Kleeberg and Kozerski, 1997).

The observed spatial and temporal pattern of nitrogen retention is not easy to explain. One obvious feature emerging in lakes B, C, E, and F is that highest nitrogen losses occur already in spring, long before water temperature or plankton biomass reach their maximum values (Fig. 5). Possibly, this could be explained by the dominance of diatoms in spring and early summer. Because this group of algae suffers from higher sinking losses compared with other phytoplankton, diatom blooms should result in enhanced sedimentation of $\mathrm{N}$. Furthermore, nitrification, the crucial step prior to denitrification (Kemp and Dodds, 2002; Kern et al., 2002), may be enhanced in spring due to deeper penetration of oxygen into the sediment.

Another phenomenon observed in these lakes is a depression in $k_{\mathrm{TN}}$ values in late summer (Fig. 5), which possibly can be attributed to nitrogen fixation by blue-green algae. As detailed species information are unavailable, this can hardly be proven by monitoring data. However, data show that the maximum of cyanobacteria biomass usually occurs in the relevant time. Taking into account the very low nitrogen to phosphorus ratios at many of the monitoring stations (TN/TP $<5$ from August-October, DIN/SRP $<1$ in August and September) the occurrence of nitrogen fixing blue-green algae seems likely (see Windolf et al., 1996, for a discussion). Low settling rates could alternatively be responsible for a decrease in $\mathrm{N}$ retention. In case of the Teltowkanal, the low seasonal variation in $k_{\mathrm{TN}}$ is probably attributed to a steady supply of nitrate (about $80 \%$ of TN) by several large wastewater treatment plants accompanied by increased water temperatures in winter.

\subsection{Adequateness of the modeling approach}

The fate of nutrients in natural waters is determined by a large number of biologically driven transformation and storage processes. Many of the processes are known in principle, but often key parameters can hardly be measured with a sufficient spatial and temporal resolution and accuracy. Settling velocities, resuspension rates or physiological characteristics of the different groups of plankton (growth rates, cell-internal stoichiometry, etc.) are just common examples. Some mechanisms, especially those related to the phosphorus release from lake sediments, are in the focus of limnological research since the middle of the 20th century. Although many modeling concepts for $\mathrm{P}$ release have been suggested (e.g. Kozerski et al., 1984; Van der Molen, 1991) the relevance of the different involved processes is still under discussion. A breakthrough in the establishment of transferable relations between sediment characteristics and internal $\mathrm{P}$ loading has not yet been made (Søndergaard et al., 2003). In consequence, the selection of an appropriate level of model complexity is the real challenge in aquatic nutrient simulations. This is true for mesoscale applications in particular.

The model concept presented in Sect. 3.3 and 4.3 reflects the simplifications which were necessary to allow the prediction of TP and TN concentrations under the constraints of limited process understanding and data availability. In order to point out the limits of the model's applicability as well as potential sources of uncertainty, some of the key assumptions (see Sect. 4.3) are recapitulated here:

First of all it should be realized that the model equations presented in Sect. 4.3 account for a limited part of the phosphorus cycle only - the release of $\mathrm{P}$ which has accumulated during a period of higher external loading. Since the model does not explicitly describe the settling of organic matter and sediment diagenesis it provides no means to simulate how the observed phosphorus excess (PX) built up in the past. If the model would account for the permanent storage of a fraction of settled organic matter in the sediment (incomplete degradation), the predicted long term phosphorus concentrations are expected to become slightly lower for all scenarios.

We assumed a linear relationship between PX and the phosphorus release rate. If this is accepted, the quantification of the sediment phosphorus excess must be considered as the primary source of potential errors in model predictions. Uncertainty is due to both, the method how PX is derived from sediment properties (Sect. 4.2) as well as the necessary extrapolation of data from a single core sample to large sediment areas. As Fig. 10 reveals, the decline in internal loading due to a continued decay of PX could perceptibly affect the phosphorus concentration in the Havel River within a decade. The sensitivity of the results to errors in the estimated initial values of PX is however quite large (error bars in Fig. 10). The analysis of a greater number of core samples, including deeper sediment layers, would be necessary to quantify the size of PX more reliably.

We have to stress that the proposed model concept is suitable for the analysis of reduced emission scenarios only, as long as the lowering in the external $\mathrm{N}$ or $\mathrm{P}$ load is moderate. In case of nitrogen this constraint is less strict due to the use of a theoretical founded first-order approach (Sect. 3.3) which gave satisfactory results under transient external $\mathrm{N}$ loading in the 1990s. The constraint is more severe with respect to phosphorus, as in the model, the rate of sediment $P$ release is unrelated to the external $P$ input. At least three 
feedback mechanisms between internal and external loading might be of relevance in reality.

One feedback is due to the fact that the diffusive P flux between sediment and water depends on both, the SRP concentration in the pore water and the pelagic. In November 2005, we determined a median SRP concentration in the top $6 \mathrm{~cm}$ of sediment of $3.9 \mathrm{mg} \mathrm{l}^{-1}$ for the Havel Lakes and even higher values are to be expected in summer. Since the pelagic concentrations are about one order of magnitude smaller (Fig. 6) it is obvious that the diffusive P flux should be rather insensitive to a reduction of the dissolved $\mathrm{P}$ concentration in the water body. The significance of other feedback mechanisms is much harder to predict: If the production and settling of organic matter would decline due to reduced nutrient availability, it seems logical that a bigger amount of "old" organic phosphorus which has accumulated in the sediment during the period of higher external loading could then be mineralized. However, a contrary reasoning is also possible if one considers that reduced settling of degradable organic matter results in reduced consumption of oxygen and nitrate in the top sediment. This in turn could diminish the release of redox-sensitive bound P. To get an estimate of the maximum potential error due to neglected feedback mechanisms, we repeated the simulation of scenario P1 and P2 with $\mathrm{P}$ release rates that were increased proportional to the reduction in external P loads (T-shaped error bars in Fig. 10). The obtained results should be considered as a "worst case", because the diffusive flux is rather insensitive to decreased external P loads (see above) and the other two feedbacks discussed might compensate each other to some extend.

One should notice that the inclusion of all key processes involved in the aquatic $\mathrm{P}$ cycle cannot be achieved by making minor changes to the model equations presented in Sect. 4.3. Instead, a full-fledged lake ecosystem model would need to be applied. In fact we implemented a standard variablestoichiometry algae-nutrient model based on the work of Hamilton and Schladow (1997) and Ambrose et al. (2001) including a single-layer sediment compartment. The modeling environment introduced in Sect. 3.3 makes this rather easy. However, we had to realize that this more sophisticated approach cannot produce more reliable results if most of the over 30 parameters need to be estimated from the literature or a very limited number of observations. We therefore returned to the simple formulation presented in Table 3 which certainly has severe limitations due to its implicit assumptions but gains from transparency on the other hand.

We believe that every model - whether it relies on a simple conceptual or a fully mechanistic approach - will certainly run into trouble if nutrient availability drops to a level where distinct changes in the overall structure of the ecosystem appear (e.g. significant changes in the composition of the plankton community, re-establishment of macrophytes, etc.). A unique, transferable pattern of the recovery of shallow lakes has not been identified so far (Søndergaard et al., 2002).

\subsection{Inferences for water quality management}

The magnitude of present internal phosphorus loading (Sect. 4.1) and the scenario simulations from Sect. 4.5 suggest that summer $\mathrm{P}$ concentrations cannot be reduced to a level that results in a limitation of primary production within the focused time period (until 2015). Even under scenario P2, which assumes a reduction in phosphorus emissions by about $35 \%$, the average concentration over the vegetation period amounts to $0.14 \mathrm{mg} \mathrm{TP} \mathrm{l}^{-1}$ after 10 years of continued P loss from sediments (average for April-September in years 10-13 of the simulation period at station Hv0200). Only in spring, when internal loading is still insignificant (Fig. 4), much lower phosphorus concentrations of about $0.07 \mathrm{mg}$ TP $1^{-1}$ might be reached (see Fig. 11). At a SRP/TP ratio of 0.3 (spring data from lake E) the corresponding SRP concentration is about $0.02 \mathrm{mg} \mathrm{l}^{-1}$. According to Sas (1989) an average SRP concentration lower than $0.01 \mathrm{mg} \mathrm{l}^{-1}$ over the entire vegetation period would be necessary to indicate phosphorus limitation of the phytoplankton. On the other hand, half-saturation concentrations used in Michalis-Menten type models of phytoplankton growth (Bowie et al., 1985) suggest that a prevention of algal blooms in the early season is possible under scenario $\mathrm{P} 2$.

As studies on the nearby Müggelsee (Spree catchment) by Köhler et al. (2000) suggest, initial nutrient concentrations in spring might also affect the succession of plankton later in the year. Anyhow, we believe that overall primary production could only be limited by phosphorus after P stripping from the sediments has continued for several decades. The implementation of drastic measures of emission control in all parts of the catchment is another prerequisite.

The scenario of reduced nitrogen emissions from nonpoint sources revealed that a significant decrease in the average TN concentration of the Lower Havel River could be achieved if the suggested measures were taken in all subbasins, including the Spree catchment. In the present situation (recall Fig. 6) a further reduction in nitrogen loads appears to be the only method which could allow phytoplankton blooms in summer to be controlled. The fact that we found statistically significant positive correlations between the upper quartiles of summer DIN and chlorophyll-a concentrations might indicate the occurrence of temporary $\mathrm{N}$ limitation in recent years. However, the causality of these correlations needs to be verified yet and nutrient enrichment experiments (e.g. Weithoff and Walz, 1999) might be required therefor. Whatever the result may be: In our opinion it is uncertain whether a further decrease in $\mathrm{N}$ loading alone could really induce a severe depletion of available nitrogen over longer periods of time. In a worse case, nitrogen shortage could be compensated by a shift in the composition of the phytoplankton towards N-fixing cyanobacteria. The danger of this undesired effect exists as long as $\mathrm{P}$ concentrations remain high and thus, $\mathrm{N}: \mathrm{P}$ ratios are low. 


\section{Conclusions}

We were able to show that the nutrient concentrations in the studied river-lake system are significantly influenced by the retention of nitrogen as well as phosphorus release from sediments. In the evaluation of management options aimed at improving the trophic and ecological state of lowland rivers, such as the Havel River, these internal processes must be taken into account. From the analysis of monitoring data and subsequent model simulations we conclude that attempts to lower the availability of phosphorus will be counteracted by internal $\mathrm{P}$ loading in the time frame available for implementing measures according to the EU-WFD (until 2015). Nevertheless, it seems likely that the impact of $P$ release will noticeably ease off within the next two decades. Even then, drastic measures of emission control will be required if nutrient limitation of primary production is to be reestablished. For the time being we suspect that efforts to further reduce nitrogen loads could be more effective than a moderately decreased $\mathrm{P}$ input. However, we are convinced that the emissions of both nutrients, $\mathrm{N}$ and $\mathrm{P}$, should better be reduced in parallel.

It should have become obvious from Sect. 4.2 and 4.3 that a reliable quantification of the sediment phosphorus excess is a crux in the prediction of future $\mathrm{P}$ concentrations in the Havel River. In order to further qualify the results of the conducted scenario analyses, the collection of a greater number of sediment core samples of sufficient length seems necessary. On all accounts, a regular monitoring of sediment properties at different times of the year would be desirable as this could help us to better identify the mechanisms behind the observed seasonal pattern of $\mathrm{P}$ release. Also, the assumption on the rate and grade of organic $P$ recycling could be validated if settling rates are monitored in parallel. Finally, experiments on the reaction of different $\mathrm{P}$ pools (e.g. $\mathrm{Fe}-, \mathrm{Ca}-$, and organic-bound fraction) to continued $\mathrm{P}$ export or variations in boundary conditions (e.g. altered supply of fresh organic matter or nitrate) could help to develop a more mechanistic model of the $\mathrm{P}$ cycle in the Havel River.

In our opinion, the developed water quality simulation program TRAM proved to be a valuable tool for both the selection of the appropriate model approach and the actual simulation of different scenarios. The concept of user-defined variables and equations (Sect. 3.3) makes it very convenient to test model formulations of different complexity for their applicability to a specific water quality problem. Although some features still need to be added to the current version of TRAM, we believe that it could serve as a valuable extension to existing catchment models in the analysis of water quality management issues. It is planned to make TRAM freely available at a later stage of development and documentation.

Acknowledgements. We thank the federal and state water authorities (BfG, LUA and WSA Brandenburg) for access to water quality monitoring data and hydrological time series as well as the German Federal Ministry of Education and Research for funding this study. We acknowledge the work of the "catchment modeling group", namely M. Biegel, T. Gräff, and A. Habeck, who ran the SWIM and ArcEGMO-Urban simulations. The set of management scenarios was established by J. Jacobs, R. Thiel, and W. Wendler. We also thank two anonymous referees for their very constructive comments.

Edited by: A. Ghadouani

\section{References}

Ambrose, R. B. J., Wool, T. A., Martin, J. L., Shanahan, P., and Alam, M. M.: WASP - Water quality analysis simulation program, Version 5.2-MDEP, Model documentation, Environmental Research Laboratory \& AScI Corporation, Athens, Georgia, 2001.

Behrendt, H. and Opitz, D.: Retention of nutrients in river systems: Dependence on specific runoff and hydraulic load, Hydrobiologia, 410, 111-122, 2000.

Biegel, M., Schanze, J., and Krebs, P.: ArcEGMO-URBAN - Hydrological model for point sources in river basins, Water Science and Technology, 52, 249-256, 2005.

Bowie, G. L., Mills, W. B., Porcella, D. B., Campbell, C. L., Pagenkopf, J. R., Rupp, G. L., Johnson, K. M., Chan, P. W. H., Gherini, S. A., and Chamberlin, C. E.: Rates, constants and kinetics formulations in surface water quality modeling (2nd ed.), Tech. Rep. EPA/600/3-85/040, U.S. Environmental protection agency, 1985.

Chapra, S. C.: Surface water quality modeling, McGraw-Hill, 1997.

Hamilton, D. P. and Schladow, S. G.: Prediction of water quality in lakes and reservoirs. Part 1 - Model description, Ecological Modelling, 96, 91-110, 1997.

Hoffmann, A.: Mathematical modeling of phosphorus dynamics in rivers with special regard to phosphorus remobilization from sediment, Master's thesis, BTU Cottbus, 1999.

Hupfer, M.: Bindungsformen und Mobilität des Phosphors in Gewässersedimenten, in: Handbuch Angewandte Limnologie, edited by Steinberg, C., Bernhardt, H., and Klapper, H., chap. IV-3.2, Ecomed, 1995.

Hupfer, M. and Gächter, R.: Influence of hypolimnetic oxigenation on phosphorus in Lake Sempach, Switzerland (in German with English abstract), in: Verfahren zur Sanierung und Restaurierung stehender Gewässer, edited by Jaeger, D. and Koschel, R., vol. 8 of Limnologie aktuell, pp. 99-114, Gustav Fischer Verlag, 1995.

Hupfer, M. and Lewandowski, J.: Retention and early diagenetic transformation of phosphorus in Lake Arendsee (Germany) consequences for management strategies, Arch. Hydrobiol., 164 (2), 143-167, 2005.

Jacobs, J. and Jessel, B.: Design of landuse scenarios for river basin management (in German), pp. 117-121, UVP-Report 3+4, UVPGesellschaft e.V., 2003.

Jensen, H. S., Kristensen, P., Jeppesen, E., and Skytthe, A.: Iron:phosphorus ratio in surface sediment as an indicator of phosphate release from aerobic sediments in shallow lakes, Hydrobiologia, 235/236, 731-743, 1992a.

Jensen, J. P., Jeppesen, E., Kristensen, P., Christensen, P. B., and Søndergaard, M.: Nitrogen loss and denitrification as studied in relation to reductions in nitrogen loading in a shallow hypertrophic lake, Int. Revue ges. Hydrobiol., 77, 29-42, 1992b. 
Jeppesen, E., Kristensen, P., Jensen, J. P., Søndergaard, M., Mortensen, E., and Lauridsen, T.: Recovery resilience following a reduction in external phosphorus loading of shallow eutrophic Danish lakes: Duration, regulating factors and methods for overcoming resilience, Mem. Ist. ital. Idrobiol., 48, 127-148, 1991.

Kemp, M. J. and Dodds, W. K.: The influence of ammonium, nitrate, and dissolved oxygen concentrations on uptake, nitrification, and denitrification rates associated with prairie stream substrata., Limnol. Ocena ogr., 47, 1380-1393, 2002.

Kern, J., Kreibich, H., and Darwich, A.: Nitrogen dynamics of the Amazon flood plain in relation to the flood pulse of the Solimöes River., in: The Ecohydrology of South American Rivers and Wetlands, vol. 6 of IAHS Special Publications, pp. 35-47, IAHS, 2002.

Kleeberg, A.: Die Sanierung/Restaurierung des Großen Müggelsees - mit oder ohne eine Baggerung der phosphorreichen Sedimentschichten?, in: Verfahren zur Sanierung und Restaurierung stehender Gewässer, edited by: Jaeger, D. and Koschel, R., vol. 8 of Limnologie aktuell, pp. 281-293, Gustav Fischer Verlag, 1995.

Kleeberg, A. and Kozerski, H. P.: Phosphorus release in lake Grosser Müggelsee and its implications for lake restoration, Hydrobiologia, 342, 9-26, 1997.

Köhler, J., Behrendt, H., and Hoeg, S.: Long-term response of phytoplankton to reduced nutrient load in the flushed Lake Müggelsee (Spree system, Germany), Archiv für Hydrobiologie, $148,209-229,2000$.

Kozerski, H., Behrendt, H., Schellenberger, G., and Mohaupt, V.: Testing of a complex ecological model for shallow water bodies, Ecological Modelling, 26, 103-113, 1984.

Kozerski, H. P. and Kleeberg, A.: The sediments and benthicpelagic exchange in the shallow lake Müggelsee (Berlin, Germany), International Review of Hydrobiology, 83, 77-112, 1998.

Kronvang, B., Svendsen, L. M., Jensen, J. P., and Dorge, J.: Scenario analysis of nutrient management at the river basin scale, Hydrobiologia, 410, 207-212, 1999.

Krysanova, V., Wechsung, F., Arnold, J., Srinivasan, R., and Williams, J.: SWIM (Soil and Water Integrated Model), User manual, PIK Report No. 69, Potsdam Institute for Climate Impact Research, http://www.pik-potsdam.de/pik_web/ publications/pik_reports/reports/reports/pr.69/pr69.pdf, 2000.

Nürnberg, G.: Prediction of phosphorus release rates from total and reductant-soluble phosphorus in anoxic lake sediments, Can. J. Fish. Aquat. Sci., 45, 453-462, 1988.

Pant, H. K. and Reddy, K. R.: Phosphorus sorption characteristics of estuarine sediments under different redox conditions, Journal of Environmental Quality, 30, 1474-1480, 2001.

Press, W. H., Teukolsky, S. A., Vetterling, W. T., and Flannery, B. P.: Numerical recipes in Fortran 90 - The art of parallel scientific computing, Cambridge university press, 2 edn., 2002.

Reichert, P.: AQUASIM 2.0 - Computer program for the identification and simulation of aquatic systems, User manual, EAWAG, www.aquasim.eawag.ch, 1998.

Reichert, P., Borchardt, D., Henze, M., Rauch, W., Shanahan, P., Somlyody, L., and Vanrolleghem, P. A.: River water quality model No. 1, IWA Publishing, 2001.
Rohde, E.: On the problem of phosphorus release from sediments of the Havel Lakes (in German), in: Die Havel, vol. 8 of Studien und Tagungsberichte, pp. 57-60, Landesumweltamt Brandenburg, 1995.

Sas, H. (Ed.): Lake restoration by reduction of nutrient loading: Expectations, experiences, extrapolations, Academia Verlag, 1989.

Scheffer, M.: Ecology of shallow lakes, Chapman \& Hall, 1 edn., 1998.

Schettler, G.: The sediments of the Havel Lakes and their seasonal dynamics (in German), in: Die Havel, vol. 8 of Studien und Tagungsberichte, pp. 46-57, Landesumweltamt Brandenburg, 1995.

Schreiber, H., Behrendt, H., Constantinescu, L. T., Cvitanic, I., Drumea, D., Jabucar, D., Juran, S., Pataki, B., Snishko, S., and Zessner, M.: Nutrient emissions from diffuse and point sources into the River Danube and its main tributaries for the period of 1998-2000: Results and problems, Water Science and Technology, 51, 283-290, 2005.

Seitzinger, S. P.: Denitrification in freshwater and coastal marine ecosystems: Ecological and geochemical significance, Limnol. Ocenaogr., 33, 702-724, 1988.

Senat: Abwasserbeseitigungsplan Berlin (Wastewater management plan for the city of Berlin, in German), Tech. rep., Senatsverwaltung für Stadtentwicklung Berlin, 2001.

Søndergaard, M., Jensen, J. P., Jeppesen, E., and Møller, P. H.: Seasonal dynamics in the concentrations and retention of phosphorus in shallow danish lakes after reduced loading, Aquatic Ecosystem Health and Management, 5, 19-29, 2002.

Søndergaard, M., Jensen, J. P., and Jeppesen, E.: Role of sediment and internal loading of phosphorus in shallow lakes, Hydrobiologia, 506, 135-145, 2003.

Svendsen, L. M., Kronvang, B. K., Laubel, A. R., Larsen, S. E., and Andersen, B.: Phosphorus retention in a Danish lowland river system, Verh. Internat. Verein. Limnol., 26, 956-962, 1998.

USACE-HEC.: HEC-RAS River Analysis System User's manual, Version 3.1, http://www.hec.usace.army.mil/software/hec-ras/ hecras-hecras.html, 2002.

Van der Molen, D.: A simple, dynamic model for the simulation of the release of phosphorus from sediments in shallow eutrophic systems, Water Research, 25, 737-744, 1991.

Van Griensven, A. and Bauwens, W.: Concepts for river water quality processes for an integrated river basin modelling, Water Science and Technology, 48, 1-8, 2003.

Weithoff, G. and Walz, N.: Problems in estimating phytoplankton nitrogen limitation in shallow eutrophic lakes, Hydrobiologia, 408/409, 367-373, 1999.

Welch, E. B. and Cooke, G. D.: Internal phosphorus loading in shallow lakes: Importance and control, Lake and Reservoir Management, 21, 209-217, 2005.

Windolf, J., Jeppesen, E., Jensen, J. P., and Kristensen, P.: Modelling of seasonal variation in nitrogen retention and in-lake concentration: A four-year mass balance study in 16 shallow Danish lakes, Biogeochemistry, 33, 25-44, 1996. 